\title{
Artifacts as Social Agents
}

\author{
Philip Brey
}

\section{Introduction: The agency of artifacts}

Do artifacts act? Should agency be assigned to them in accounts of social change? Or are human beings and social structures like groups and organisations the only social agents? This is a pivotal question for technology studies, but one that has not received an unequivocal answer so far. On the one hand, the literature in technology studies is filled with examples and cases that suggest that technological artifacts and systems do act: they have been claimed to prescribe behaviours, constrain political arrangements, induce cultural beliefs and practices, and shape aspects of their social context. On the other hand, the social constructivist orientation of a large part of technology studies seems to be incompatible with an attribution of agency to artifacts, because it maintains that alleged properties of artifacts can be reduced to the actions and interpretations of social groups.

There is general agreement in technology studies that the introduction and use of a new technology is often accompanied by significant changes in its social context. Such changes may include changes in individual and collective behaviours, attitudes and beliefs, in social statuses and roles, and in social structures and institutions. This generally accepted idea goes against the notion that technologies are neutral, in the sense that they are mere means-toends that function to perform certain tasks more quickly, efficiently or powerfully, and that a proper analysis of them focusses on their function as a means to chosen ends. It is a core belief of technology studies that technologies must also be understood, and perhaps centrally, as building blocks of society and as instigators of social change, in ways that are often unrelated to their intended functions.

But here the agreement stops. One may agree that the widespread use of the birth-control pill has been accompanied by, and can be correlated with, sexual liberation and greater freedom for women, and that without the pill these 
changes would not have occurred. But then one may go on to seriously disagree about the agentive role of the pill in this whole process. On the one hand, one may present a narrative in which the pill is a powerful actor, a hero (or villain) that single-handedly gave sexual freedom to generations of liberated women. In this epic, the pill may be depicted as a liberator, with sexual freedom written all over its chemical code. It only needed a chance to act. Yet, one may also tell a story in which sexual liberation is not created by a little pill, but by people who were already in the process of a revolution when a little chemical entered the scene, and which made it play an important role by attributing meanings to it and by involving it in real-life practices. In this story, there is no such thing as a pill with inherent liberating powers. The pill, as a catalyst for social change, is a social construction. Pills do not act; they are inherently powerless and amorphous. But people can make them look as if they have powers and agency by assigning interpretations to them and implicating them in practices.

These two perspectives characterise two of the three dominant perspectives in technology studies concerning the nature and status of technological artifacts and systems. They are the realist perspective, according to which artifacts have inherent properties and agency can be attributed to them in a straightforward way, and the social constructivist perspective, according to which artifacts do not have inherent properties but only imputed or attributed properties, and any imputed agency of them ultimately derives from the interpretations and behaviour of individuals and social groups.

Besides these two perspectives, there is a third, which I shall call the hybrid perspective, which has been taken up most forcefully in actor-network theory (Callon 1987; Latour 1987; Callon and Latour 1992). In this perspective, the neat distinction between the social and the technical or material, accepted by both realists and social constructivists, should be abolished, and artifacts and their properties should be analysed neither as objective facts nor as mere social constructions, but as both real and constructed. Artifacts and their properties emerge as the result of their being embedded in a network of human and nonhuman entities. It is in this context that they gain an identity and that properties can be attributed to them. Hence they are constructed. But since this network is not a purely social network (it includes nonhuman entities as well), they are not socially constructed. And since they are participants in the network as well, one can attribute agency to them, even though this agency derives from their place in the whole network.

In this essay, I shall critically evaluate these three dominant perspectives on the agency of artifacts. My conclusion will be that none of these perspectives provides a satisfactory account of the agency of artifacts, and I shall close by sketching an alternative perspective, which I call differentiated constructivism. 


\section{Realism}

Realists maintain that social change accompanying the use of a technology can often be causally correlated with the design structure of these technologies themselves, and that therefore these technologies can be properly analysed as possessing powers for effecting change, and that when these powers are exhibited, the technologies are properly analysed as acting. Moreover, the agency of artifacts is held to be irreducible to the agency of human agents involved in their production, regulation or use: it is a feature of artifacts themselves, just like your action of buying a sandwich is not reducible to the actions of others (although in many ways shaped by the society you live in).

There are many examples in the relevant literature that seem to support this realist position by showing how the design of a technology constrains or enables practices, beliefs, or social configurations. In all these cases, one is tempted to say that it is the technology that enables the occurrence of these practices, beliefs or configurations, and hence that the cited artifacts or systems have agency. Latour (1992), for one, discusses how mundane artifacts, like seatbelts and hotel keys, may prompt their users towards certain behaviour. A hotel key, for example, has a heavy weight attached to it in an attempt to encourage hotel guests to bring their key to the reception desk upon leaving their room. Sclove (1995) points out that modern sofas with two or three separate seat cushions define distinct personal spaces, and thus work to both respect and perpetuate modern Western culture's emphasis on individuality and privacy, this in contrast to Japanese futon sofa-beds, for example. Winner (1980) discusses nuclear power plants, which, he claims, require centralised, hierarchical managerial control for their proper operation. They cannot be safely run in an egalitarian manner, unlike, for example, solar energy technology. In this way, nuclear plants require that a particular form of social organisation be adopted for their operation.

Within a naive form of realism, which may be termed technological essentialism, technologies may have inherent powers that manifest themselves in any context of use. Technologies may be inherently authoritarian, democratic, unjust, deskilling, repressive, egalitarian, individualistic, masculine, Western, etc. Langdon Winner claimed that a technological essentialist position is correct for at least some technologies. He argued that some technologies are "inherently political" in that they have specific political consequences that will manifest themselves in any setting. The atom bomb, for example, is inherently political because "[a]s long as it exists at all, its lethal properties demand that it be controlled by a centralised, rigidly hierarchical chain of command closed to all influences that might make its workings unpredictable. 
The internal social system of the bomb must be authoritarian; there is no other way" (Winner 1980,34). Other cases of technological essentialism in the literature include Ivan Illich's (1973) distinction between convivial and anticonvivial or manipulatory tools, Lewis Mumford's (1964) distinction between democratic and authoritarian technology, and feminist analyses of technology as inherently masculine or inherently patriarchal (e.g., Corea et al. 1985; Mies 1987; Merchant 1980).

Technological essentialism tends to underestimate the interpretive flexibility of technology and is vulnerable to counterexamples which show that such technologies, when used in a different cultural or social context, may often exhibit properties that are thought to be incompatible with their claimed essence. A more sophisticated variety of realism, which I shall call contextual realism, is more sensitive to the context-relativity of the workings of many technologies. Contextual realism holds that artifacts may impose constraints on their environment that derive from their physical design properties, but also postulates that such constraints will often differ in different environments or settings. Take, for example, Winner's (1980) famous, if contested, case of the Long Island bridges. ${ }^{1}$ Winner claimed that these bridges were built at a height of often no more than 9 feet $(2.75 \mathrm{~m})$, a height that prevented buses passing under them, hence effectively blocking access to Long Island by public transport. Because most blacks depended on public transport at the time these bridges were constructed, the bridges consequently worked to bar access to Long Island for many blacks. The relevant constraint imposed by these bridges is hence that blacks were largely excluded from accessing Long Island (especially its popular public parks).

In a contextual realist analysis of this case, it is a feature of the material design of these bridges (their construction at a height of 9 feet) that was responsible for the constraint these bridges imposed on their environment, viz. making it impossible for buses from New York to access Long Island, and thereby barring easy access to Long Island for most blacks. Clearly, being discriminatory against blacks is not an intrinsic property of bridges in general, nor specifically of bridges built at a height of 9 feet. In many conceivable settings, bridges with a height of 9 feet would not be discriminatory against blacks. For example, they would not be in settings where blacks are not economically disadvantaged or have alternative modes of public transportation available to them, or where buses are less than 9 feet high.

So although 9-foot-high bridges are not intrinsically discriminatory against blacks, they may become discriminatory in particular settings, particularly in situations in which they are placed in areas in which blacks (and not whites) use buses as their predominant mode of transport, in which these 
buses are more than 9 feet high, and in which blacks cannot easily switch to alternative modes of transport. The setting constituted by New York and Long Island in the 1960s constitutes this type of setting, and hence the 9-footbridges in them are discriminatory. This discriminatory character derives from the relation or "fit" between the physical design features of these bridges (i.e., their being built at a height of 9 feet) and their setting or context of use. ${ }^{2}$

Other cases discussed by Winner also fit a contextualist analysis. For example, he deals with pneumatic molding machines used at a 19th-century reaper manufacturing plant in Chicago. In that particular setting, these machines had the intended effect of breaking the union, which represented the skilled workers in the plant, because readers undermined the power of skilled workers as they could also be used by unskilled workers, an outcome that benefited the owner of the plant. Clearly, helping to break a union (or even of undermining the power of skilled workers) is only something pneumatic molding machines can do in particular settings, that is, in plants in capitalist societies in which skilled workers are united in unions.

If the agency of technologies is hence context-relative, as contextual realism claims it is, would it not be more proper to say that agency does not reside in the artifact but rather in the whole setting, that is, the artifact plus (relevant aspects of) the context in which it is used? Contextual realists would, I believe, say that the attribution of agency to the artifact alone is justified because the artifact functions as the major independent variable. That is, whereas the agency is also dependent on other variables that are found in the environment of the artifact, the artifact itself is most directly and specifically linked to the changes that occur. Thus, whereas the bridges over Long Island would not have discriminatory politics if blacks in New York were not economically disadvantaged, the immediate cause of their being barred is clearly not the economic politics of New York, but the construction of the bridges. Thus, it is the bridges that are discriminatory, even though they can only have the discriminatory politics they have because of various other contextual factors.

Realists emphasise the physical structure and operation of artifacts and correlate social change with this structure and these operations. By focussing on the physical design of artifacts, they play down the role of social factors in effecting change. Although social factors may play an auxiliary role in contextual realism (e.g., social factors that are responsible for the poverty of many blacks in New York, in the case of the Long Island bridges), they are usually assigned a mere background role. One type of social factor that is particularly played down in realist analyses is that of social representation. The social representation of artifacts is the process of constructing shared (i.e., social) representations of them and their properties. Such social representations deter- 
mine to a significant extent how an artifact is perceived by individuals, the specific features (including functions and relations to other entities) that are recognised in it, the way in which these features are evaluated, the way in which the artifact is ultimately used, and the consequences that result from this use.

Consider, for example, pink baby clothes for girls. Such clothes do not just have the intended function of clothing the child, they also impose a gender constraint by perpetuating a gender stereotype: they symbolise femininity, along with associated traits like sweetness, cuteness, passivity, etc. In this way, they promote a gender stereotype and promote the treatment of the baby girl in accordance with this stereotype. A realist analysis of this gender constraint appears to be incorrect. Pink baby clothes do not somehow physically induce a gendered treatment of the baby girls who wear them. It is rather the widely accepted social representation of pink as symbolising femininity and stereotypical female qualities that generates this particular treatment. The colour pink does not wear this symbolic meaning on its sleeve. In contrast, this gendered social representation of pink is a social construction that only exists in certain societies.

Another example, discussed in Pfaffenberger (1992), is that of the Victorian hallway bench, used in the hallway of Victorian houses to seat servants and tradesmen while they waited. The bench itself was plain and uncomfortable, without upholstery, whereas the hallway often included an ornate mirror and delicately carved hat hooks. The bench served to mark social status: it reminded servants of their inferior status, while also underscoring the superior status of the master, through the mirror and hat hooks below which the servants were seated. Here, again, the hardness of the bench and the ornateness of the mirror and hat hooks do not somehow physically require the persons who are seated on them to have inferior status, or the owner of them to have superior status. It is rather that social representations existed of higher and lower social statuses, including representations of attributes that were considered "fitting" for the specific class in question. It was considered "fitting" for the lower classes to make use of "plain" artifacts, whereas the higher classes used "luxurious" artifacts. Because the bench was socially represented as "plain" and this social representation was associated with "lower class" (and the "luxurious" mirror and hat hooks with the higher class of its owner), the bench (and the mirror and hat hooks) could be used to mark social class.

Even when it may seem that social change is due to the physical design of a technology, social representation processes often play an important role. Take, for example, the case of the atom bomb, which, Winner claims (1980), imposes a political constraint: it requires a strong, authoritarian security net- 
work because of its lethal properties, which means that there is a danger of theft or terrorist acts. But, in a sense, it is not the objective lethal properties of the bomb that impose this constraint, but rather a social representation of the bomb as having lethal properties and of posing risks when not guarded well. It is these perceptions of lethality and risk, and not any objective features of the artifact itself, that are the immediate cause of certain actors organising an authoritarian security network about the bomb. These perceptions of lethality and risk reduce resistance from third parties to this authoritarian network by legitimising its existence.

The problem with realist perspectives is that they systematically underestimate the importance of the mediating role of social representations between the technology and its social context. Technologies rarely force behaviour, in the sense of physically moving one's arm or stopping one's feet. Also, they do not tell people which new configurations or practices they enable. Instead, the direct basis of many social changes accompanying the use of a technology seems to lie in social representations of what a technology is and what it does. Importantly, these representations do not passively mirror the "objective properties" of the technology. Instead, it has often been shown in technology studies that technologies have "interpretive flexibility" (Pinch and Bijker 1987), in that people can attribute very different functions, abilities and properties to them.

\section{Social constructivism}

Whereas realists tend to play down the role of social representations in the constitution of technological agency, social constructivists place all the emphasis on these. It is claimed that social representations not only play a major role in the constitution of agency, they also fully determine it. Alleged technological agency is wholly the product of the way in which artifacts are socially represented (and hence used). The examples of the baby clothes, the Victorian bench and the atom bomb in the previous section demonstrate the plausibility of this position.

Social constructivists maintain that artifacts have interpretive flexibility: different interpretations, or social representations, can be assigned to them, and these different interpretations assign different properties to them, not just regarding their function, but also regarding their technical content. Different social groups will occasionally represent an artifact quite differently. At other times, however, processes of social negotiation lead to closure: one social representation tends to dominate, henceforth determining the way the 
artifact is interpreted and consequently the human practices that evolve around it (Pinch and Bijker 1987). This whole process is sometimes described by a textual metaphor: artifacts are texts that allow for different readings of them (Woolgar $1991^{\mathrm{a}}$ ). When closure is reached, however, one dominant reading of the text prevails, and alternative readings of them may become difficult. In a social constructivist conception of affordances and constraint, then, these are not constituted by inherent design features of the artifacts themselves, but rather by dominant social representations or "readings" of them. The design features of artifacts that seem to be responsible for constraint are actually social constructions.

Perhaps the most fully developed social constructivist theory of the agency of artifacts has been developed by Bryan Pfaffenberger (1992). Pfaffenberger is specifically concerned with political agency. He argues that the political agency of artifacts derives from affordances: perceived properties of artifacts that suggest how they should be used, or, more broadly, how they should be responded to. For instance, it is a perceived affordance of a cup that it can be used to drink water, but in certain settings it may also be a perceived affordance of a cup that it can be used to emphasise one's taste in choosing decor, or to hold model airplane parts. Affordances are not objective design features of artifacts but rather social constructions, or social representations, as they depend on a selective and constructive process of "reading" certain uses or meanings into artifacts.

For a particular way of "reading" an artifact (i.e., a particular affordance) to become dominant, it must be discursively regulated. That is, the affordance must be legitimated by a sufficiently persuasive discourse. The most persuasive discourses are symbolical discourses of myth, ritual and classification, rather than the verbal discourses of proposition and argument. So, for example, the affordance of Victorian hallway benches to express class distinction and humiliate the lower classes depended on a symbolic discourse that legitimated this affordance. This symbolic discourse derived from the Victorian myth of hygiene: the plain bench was presented as an artifact that had to be used by the servant class not because it would humiliate them, but because they had been on "public conveyances" and would therefore soil upholstery with the filth of the streets.

Pfaffenberger adds that discursive regulation in itself is usually insufficient to endow artifacts with political affordances. Discursive regulation must be accompanied by secular ritual, standardised practices that follow relatively well-defined scenarios involving various acts and objects that help regulate social behaviour. It is through secular ritual that the political affordances of an artifact come to life. For example, the politics of the Victorian hallway 
bench were brought to life through ritualisation of the hallway space. This space was the site of profound decorum standards, which called for members of the master's class to be admitted into the interior of the house straightaway, while members of the servant class were seated on the bench, thereby signifying their inferiority. To sum up, according to Pfaffenberger, affordances and constraints derive from perceived affordances of artifacts, which are social representations that are legitimated by symbolic discourses and that are brought to life through secular rituals.

If affordances and constraints derive from social representations rather than from physical design features, can constraints still be legitimately attributed to artifacts, or would it be more proper to say that artifacts do not impose constraints, but that social representations external to the artifacts do? This depends on how one defines "artifact". When "artifact" is taken to mean a physical object on which particular social representations are projected, then it should be clear that artifacts do not impose constraints. Hence, Pfaffenberger's answer to the question "Do artifacts have politics?" is that, in and of themselves, they do not $(1992,294)$. However, the term "artifact" is often reinterpreted within social constructivism as not denoting independently existing physical objects, but as denoting particular social representations of artifacts. After all, social constructivists often deny that there is any objective structure underlying social representations and claim instead that reality is made up of social representations: reality is a social construction. If artifacts are defined as social constructions, then it appears that artifacts are able to act.

Against social constructivism, it may be argued that it places too much weight on social processes and wrongly neglects the role of the physical design of artifacts. For there appear to be at least some affordances and constraints that derive at least partially from physical design properties. Indeed, artifacts sometimes seem to act in such a way that social representation does not appear to play an important role. Take, for example, the Long Island bridges that prevent buses from New York going under them to Long Island. This constraint (the exclusion of buses, not the exclusion of blacks) seems to derive from the physical design features of the artifact in question. Regardless of how these bridges are interpreted by bus drivers and others, they make it impossible for buses from New York to go to Long Island, as buses cannot pass under them. Let us call constraints of this sort that seem to work by physical means alone physical constraints.

We may distinguish strong physical constraints, which physically require or prevent certain actions, events or situations, from weak physical constraints, which merely promote, discourage, or hamper. Weak physical con- 
straints are constraints that exert some amount of physical force, but can be countered, whereas strong physical constraints hold as a matter of physical law. For example, the prevention of buses going to Long Island as sketched above seems to be a strong negative constraint, as a certain event is made physically impossible. The encouragement to hotel guests to leave heavy hotel keys at the front desk by attaching weights to them is a weak positive constraint, as a certain event is made more likely to occur through physical force.

There are several types of constraints that seem to qualify as strong physical constraints:

\section{Forcingfunctions}

Forcing functions (Norman 1988, 132-38, 204-6) are physical constraints that require users to perform certain acts that not directly related to the purpose to which they want to use the artifact. An example is the forcing function imposed by the special interlock, required for a short period in history to be installed in each new car in the United States. Because of this interlock, the car would not start if the driver's and passengers' seatbelts were not fastened. So drivers had to fasten both seatbelts to be able to use the car.

Forcing functions are generally intentionally designed and are usually, though not invariably, included in the interest of safety. Norman distinguishes three types of forcing functions that are used in safety engineering: interlocks, lockins, and lockouts. Interlocks force operations to take place in proper sequence. For example, the pin on a fire extinguisher or the safety of a rifle requires certain functional acts to be performed before these devices can be used. Automated cash dispensers nowadays require users to remove their AT M card before money is issued. This order is engineered in order to help users not to forget their card. When people open the door of a microwave oven, an interlock automatically disconnects the power the instant the door is opened.

Lockins keep an operation active by preventing someone from prematurely stopping it. This seems to apply mainly to mechanical and electrical devices. For example, most computers nowadays have a "soft" on-off switch. When users turn off the computer, the power is not disconnected, but the computer first sends signals to programs to quit, checks that all files have been saved, and only then turns off the power. A lockout prevents persons from entering a place that is dangerous or otherwise off-limits, or prevents an unwanted event from occurring, by making sure that people only enter the place or use the device for the right reasons. For example, in public buildings, a bar is sometimes installed at the top of the stairs from the ground floor to the basement. This bar will help to prevent people from fleeing down the stairs into the basement when there is a fire in the building and they panic. 


\section{User-and use-excluding physical constraints}

User-excluding physical constraints are physical constraints that exclude certain users from making proper use of an artifact. Use-excluding physical constraints are physical limitations on the use of an artifact. I shall now discuss them one by one. Artifacts impose a user-excluding physical constraints when they strongly require users to have certain physical attributes or be in possession of certain physical competencies, whether these derive from their own body or from artifacts used by them, like keys, cars, or hammers. For example, doorways will prevent creatures whose waist size is greater than the size of the doorway from entering. Fifty-pound bags of cement can only be lifted by construction workers who have the requisite physical strength. Computers can only be used by individuals who are not congenitally blind, or who have equipment that can transpose computer readouts to Braille or synthesized speech.

\section{Other strong physical constraints on actors}

Next to forcing functions and user- and use-excluding physical constraints, there are all kinds of other physical constraints that may affect actors. Users of artifacts may experience all kinds of constraints that do not directly affect their ability to use the artifact in particular ways but that nevertheless constrain their behaviour. For example, the use of a car requires the user to sit down and use his or her arms and legs. While driving, it is physically impossible to stand up or turn around to face backwards. ATms require the user to obey a time limit, or else the transaction is canceled. Making use of a room with no windows implies not being able to see what is going on outside. The use of electrical appliances that are not accessible for repair or battery replacement implies that when the artifact breaks down, the user is physically prevented from making it work again. A car with two separate compartments physically prevents the driver from talking to, or touching, passengers in the back. Physical constraints may also be imposed on non-users. For example, the use of noisy machinery in construction makes it impossible for bystanders to have a normal conversation. A building may physically prevent pedestrians from seeing what is behind it.

Social constructivists have argued against the existence of physical constraints by claiming that what appear to be instances of physical constraints are actually social constructions, particular "readings" of artifacts that seem to refer to objective, physical conditions because they have become obdurate through closure. There are two variants of this argument. In the first, physical constraints are above all social constructions of the users of artifacts. Users are 
predisposed to "read" an artifact in a way that constrains them. They could, however, learn to "read" the artifact differently, after which the apparent physical constraint disappears. This argument is plausible for cases in which users seem to "misread" artifacts, or "read" them non-creatively. For example, an obese person may falsely believe that he/she cannot pass through a doorway whereas there are, in fact, ways of doing so. Against this social constructivist argument, it may be pointed out that there appear to be cases in which no change in "reading" habits seems to be able to remove the constraint. For example, it seems that no matter how bus drivers represent the Long Island overpasses, they will still not be able to drive under them with their bus.

A second version of the argument is that apparent physical constraints are really the social constructions of the analyst. Social constructivists may grant that there are physical constraints that, like Kant's things-in-themselves, impinge on the world, but may deny that these physical constraints are objectively verifiable by anyone, including the analyst. We only have reliable access to social representations, not to any reality behind them, and hence any pretenses of an analyst to have reliable knowledge of physical properties and physical constraints are misguided. The analyst who tries to divide up reality into objective physical features and socially constructed features is trying to make distinctions that cannot reliably be made (cf. Woolgar 1991 ${ }^{\mathrm{a}}$; Grint and Woolgar 1992, 1995).

For example, an analyst may observe that 2oth-century kitchens only offered room for one worker and therefore did not support the sharing of kitchen duties (Wajcman 1991, 114). However, the belief of the analyst that these kitchens only offered room for one worker may be based on her unimaginative "reading" of these kitchens. Perhaps she sets very high criteria for what kinds of actions count as an acceptable use of a kitchen, and does not consider how users may come up with creative solutions to divide up the available space in a way that makes it possible for two people to use it simultaneously. Similarly, an analyst of the Victorian hallway bench may wrongly identify certain relevant properties as objective whereas these are really dependent on his biased social representations. For example, the analyst may identify the bench as "plain", whereas its plainness is really a cultural construct. Or he may observe that members of the lower classes would often bring in filth that would stain benches with upholstery, not noticing that "filth" and "staining" do not denote objective phenomena, but imply particular value judgements.

One can object to this argument that even if users or analysts are never in possession of fully "objective" representations of artifacts, there are enough instances of physical properties or physical constraints that are so uncontro- 
versial that it seems silly not to make recourse to them in accounting for affordances and constraints. For example, it seems to be a plain fact that $10-\mathrm{ft}$. buses do not fit under 9 -ft. bridges. And whereas two people may perhaps use a small kitchen simultaneously, the same is clearly impossible for 20 people. Hence, some constraints imposed by artifacts appear to be self-evident, and incontrovertible.

Against this objection, Woolgar $\left(1991^{\mathrm{a}}, 32\right)$ has claimed that "the whole point of interpretive flexibility is that apparent 'self-evidence' and 'incontrovertibility' are social accomplishments that are subject to change. Our recourse to self-evidence merely buys into one current definition. And it would be a pity to limit the scope of the theory to technologies whose impact currently happens to be controversial". Woolgar's point is that buying into selfevident or uncontroversial "truths" about technical artifacts biases the analysis because these "truths" are actually contingent social representations. Also, it may make analyses shallow by excluding the possibility of more profound critiques of affordances and constraints that question accepted truths. For example, an analyst in Victorian times, and even a present-day observer, might have missed the fact that some properties of Victorian hallway benches, such as their "plainness" and their "better resistance to filth" are, in fact, contestable social constructions that are part of the discourse that was used to humiliate the lower classes: it draws from a particular myth on aesthetics and hygiene.

I believe that Woolgar is right that our perceptions of "objective" physical features of artifacts always involve an amount of social construction, and that serious attention should be paid to uncover particular biases in these perceptions. However, I also believe that there are limits to such reflexive activity, and that it sometimes pays too little to keep questioning the "objectivity" of certain putative physical properties or constraints. For example, it is unclear what will be the gain from deconstructions of the claim that $10-\mathrm{ft}$. buses do not fit under 9 -ft. bridges. In contrast, much can occasionally be gained if the analyst is allowed to make reference to this "fact" in an analysis. Therefore, I believe that analysts should be allowed to appeal, with caution, to physical properties and constraints in their analyses. Social constructivism cannot do this and hence cannot give a complete account of technologically induced social change. 


\section{Hybrid constructivism}

The term "hybrid constructivism" can be taken to refer to any position that adopts the principle of generalised symmetry. This is a methodological principle according to which any relevant elements referred to in an analysis (whether "social", "natural", or "technical") should be assigned a similar explanatory role and should be analysed by the same (i.e., symmetrical) type of vocabulary (Callon 1987; Latour 1987; Callon and Latour 1992; Callon, Law and Rip 1986). Hybrid constructivists (many of whom define their work as taking place within actor-network theory) analyse phenomena, such as the workings of an artifact, as the result of the activity of a heterogeneous network of entities that work to co-construct the phenomenon. These entities are not treated differently in the analysis because they are labelled as "social" (or "human") or "technical" or "natural" ("nonhuman"). All are actants (things that act) that have similar (i.e., symmetrical) explanatory roles. ${ }^{3}$

Social constructivism is criticised by hybrid constructivists for assigning a special role in analysis to social elements, such as social groups and the social representations they employ, whereas "natural" or "technical" elements, such as natural forces and technical devices, are prohibited from being explanatory factors in explanations. Hybrid constructivists also allow for technical devices and natural forces to be actants in networks through which particular phenomena are constituted. By an analysis of actant networks, any phenomenon can be shown to be a post hoc construction, the consequence of the stabilisation of a whole network of human and nonhuman actors. This does not mean, however, that these phenomena are socially constructed, because the phenomenon is not only the result of social factors. It is the result of heterogeneous elements, all of which are accounted for by the same, symmetrical vocabulary, and none of which are explicitly identified as "social", "technical", etc.

By thus rejecting the traditional distinction between nature and society (and hence between the naturally given and the socially constructed), hybrid constructivists reject a distinction maintained by both realists and social constructivists. Realists maintain that even though there are social entities, and even though some facts or objects may be socially constructed (e.g., money, marriages, and other social objects; cf. Searle 1995), there are also purely physical and technical processes, facts, and objects that may sometimes, as with technical artifacts, have been constructed by humans and may have involved human choices in their design, but have physical properties that are ontologically independent of social interpretation or negotiation. Social constructivists maintain the distinction as well, but move in a different direction than 
realists do: instead of saying that socially constructed objects have a physical basis, they argue that the natural and the technical are constructed out of the social.

Its proponents hold hybrid constructivism to be plausible because they believe that realists and social constructivists, who maintain an asymmetrical vocabulary, fail in their attempts to explain the various scientific and technical phenomena. Realists and social constructivists maintain distinctions that stand in the way of good methodology, which is methodology in which sound generalisations can be made to account for the complex interactions of people and things. Both cannot adequately account for moves "from action to behaviour, from meaning to force, from culture to nature" (Callon and Latour 1992, 361). The problem with realist analysis of technology, according to hybrid constructivists, is that it cannot shake off an unwarranted technological determinism, according to which technology by itself affects change in the world. The problem with social constructivist analyses is that nonhuman objects are left powerless; only humans act, even though technical and natural objects appear to play the role of intermediaries in all kinds of processes. As Callon and Latour conclude: "The choice is simple: either we alternate between two absurdities, or we redistribute actantional roles" (356).

The symmetrical model for the analysis of technology has perhaps been developed most fully by Bruno Latour $\left(1988^{\mathrm{a}}, 1988^{\mathrm{d}}, 1992,1995^{\mathrm{a}}\right.$; Akrich and Latour 1992). In Latour's vocabulary, no principled distinction is made between humans and nonhumans; all are actors, or actants, that are able to act, mediate, and influence. Actants are assigned competencies, that is, powers to act. The competencies of actants in a setting cannot be determined beforehand, but can only be attributed to them as the result of analysis of the whole setting in which they operate. The same is true of their performances: the concrete actions they perform in a particular setting. And, it may be added, the same is true of any generalisations, or laws, stated over the performances of actants. Notice that, in this vocabulary, the whole distinction between physical objects and human actors, physical capacities and behavioural dispositions, physical processes and human actions, and physical laws and social norms or habits disappears: there is only an interplay of actants and their performances, which are all described in the same terms.

Actants may form associations, or links. This happens when two or more actants start interacting with each other on a structural basis. For example, an association is formed between a door and a door closer when the door closer systematically closes the door after it is left open. A similar association would arise if the door closer were to be replaced by a human butler who was trained to close the door at all times. Another association would be the link between a 
traffic policeman directing traffic and a road user obeying these directions. A similar link may exist between a road user and a traffic light. Again, it does not matter in the description whether the links are between human or nonhuman actants. When multiple actants form links with each other, networks of actants emerge. The stabilisation of a network is the process by which associations in a network become stable, or solidify.

Now, Latour maintains that any fact about the competencies and performances of a particular technical artifact (or, for that matter, a scientific phenomenon, or any other entity) is the product of a network of actants that jointly work to "produce" this fact. Take, for example, the fact that a traffic light is able to direct traffic. This is not an intrinsic technical capacity of a traffic light, but is rather the result of a stabilised network of actants. These actants include the traffic light itself, but also the road users, who are disciplined to respond to changes in the traffic light in particular ways, and it includes elements of the infrastructure that support the working of the traffic light (e.g., electricity cables) and elements of the road system used by the road user (e.g., the vehicle, the asphalt under the vehicle). It is the total stabilised network of actants that ensures that the traffic light has the competence to direct traffic.

Latour developed a whole vocabulary for the analysis of such actant networks. I shall now discuss some of its key terms, beyond the ones already mentioned. Delegation, or translation, is a process by which certain actions performed by one or more actants are transferred to other actants that perform them more effectively or efficiently. ${ }^{4}$ For example, in a hotel in which guests constantly leave the front door open, it can be decided that closing the door should be delegated from the guests (who do not form a stable doorclosing link with the door) to a groom, or a door closer. When delegation indeed results in more durable associations, then it may be called an inscription (or encoding). Because machines often create more durable associations than humans do, inscription often involves the delegation of human actions to a machine. However, the embodiment in cultural tradition of the owner manual of a car is also an inscription, as the instructions in the manual will be more reliable when they are part of everyday knowledge than when they are written down in a leaflet that must be consulted continually.

Prescriptions (or affordances) are what a scene or setting, or a specific actant in a scene, forbids or permits particular actants to do. The term is most often used by Latour to describe presuppositions that technical artifacts (as embedded in, and defined by, a network of actants) have about the behaviours and attributes of their users. As Latour remarks, prescription "is very much like 'role expectation' in sociology, except that it may be inscribed or encoded in a machine" $\left(1988^{\mathrm{d}}, 306\right) .{ }^{5}$ Prescriptions need not be obeyed: the user may 
not be properly attuned to the prescriptions, and may refuse to follow up on them. For example, a traffic light expects that its users will perceive it from the street and not from one side. A hotel key with a heavy ball attached to it expects guests to return it to the front desk, but guests need not obey this prescription. Scripts are the scenarios, or roles, played by human or nonhuman actors in a setting when they obey the various prescriptions inscribed in a scene, or inscribed in a particular actant in a scene. When defined relative to an artifact, a script is the framework of action, in conjunction with the actors and the space in which they are supposed to act, which is presupposed by the artifact and any other actants that help to define its prescriptions (e.g., notices, manuals).

Actants (and scenes, and networks of actors) may also be assigned programs of actions, that is, goals that they "try" to reach and that are made the point of departure of an analysis. The associations of actants in a setting, and changes in these associations (and the competencies of actants, and hence their prescriptions) over the course of time can then be described in terms of their effect on this program of actions. For example, the scene, mentioned earlier, of the hotel door that should be kept closed may be analysed from the "keep-the-door-shut" program of actions. This may be a goal of the hotel manager, and it may become a goal of properly disciplined guests, as well as grooms and other delegates such as notices and door closers. Antiprograms are programs of action of actants that are in conflict with the program of actions chosen as the point of departure of the analysis. For example, hotel guests may be too rushed to close the door behind them, and some may even leave the door open intentionally for fresh air. A well-designed artifact (such as a good door closer) carefully anticipates various antiprograms to the degree that is able to let its own program of actions prevail over them. A program of actions is successful when the prescriptions of an artifact and its allied actants yield a script that conforms to this program of actions and is resistant to the antiprograms of other actants. To be successful in this way, artifacts must participate in a system of alliances with other actants that help issue a set of prescriptions.

So what is agency within this theoretical framework? Agency can be reduced to prescriptions issued by artifacts. Strong prescriptions are ones that the actant(s) to which the prescription is issued is/are somehow disposed to obey. Their competencies are such that they respond to the prescription by obeying it. It does not matter if the constraint is physical or symbolic (social, representational). For example, red traffic lights issue a strong stopping constraint to most drivers, because most drivers are strongly disposed to stop at a red light. Moreover, it does not matter whether the obedience of a prescrip- 
tion is willing or not; the important element is whether the prescription is sufficiently powerful. For example, a car that is wired to start only when the driver wears a seat belt may force its driver to obey the prescription "wear a seat belt (or you cannot drive the car)". Only a driver who has the competence to disable the wiring will be able to evade this prescription.

Strong prescriptions may exclude human actants (especially users) when they are unable to play the roles required of them, even if they desire to, because they lack the required competencies. For instance, an AT M may require its users to be literate, thus excluding illiterate prospective users. Alternatively, strong affordances and constraints may frustrate human actants because they are only able to play the required role by adapting (i.e., by developing the required competencies). For example, a door that is $6 \mathrm{ft}$. high requires someone who is $7 \mathrm{ft}$. high to stoop ("become a smaller person") when entering.

A weak prescription is one that may fail because the actants to which it is issued may not have the required disposition. For example, a car that flashes a warning when the driver wears no seat belt may not succeed in compelling the driver to wear a seat belt, because the driver can choose to ignore the warning light. Even physical force may only serve as a weak constraint when an actant subjected to it has the competence to resist it and carries an antiprogram against this force. For example, the Long Island bridges discussed earlier will not stop buses when the buses have the physical strength (competence) to ram through them and the bus drivers are disposed not to stop for the bridges. $^{6}$

Notice that although Latour sometimes attributes prescriptions to particular artifacts, he does not hold that these prescriptions are the result of competencies intrinsic to the artifact and that they reveal themselves in appropriate settings. This would make his approach resemble a contextual realist one. Latour maintains that competencies cannot be discovered by studying artifacts in isolation. They are inherently relational: they are realised as the product of the embedding of an artifact in a network of associated actants. When this kind of network stabilises, competencies emerge as black boxes, that is, as apparently transparent properties of actants that obscure the fact that they depend on the network of alliances of which the actant is a part. Artifacts gain their identity only within such networks, and hence technological innovation is not just the isolated development of a new artifact, but the modification and development of a network of associations of which this artifact is to be a part.

The apparent advantages of a hybrid constructivist approach over a realist or a social constructivist one are twofold. First, hybrid constructivism does not need to determine whether properties of artifacts that give rise to social changes are either objective physical features or social constructions. It does 
not need to say, for example, whether the properties of Victorian hallway benches that help demarcate class (e.g., their hardness or their plainness) are either objective properties or social constructions. Is its hardness objective or socially constructed? What about plainness? In a hybrid constructivist framework, it does not matter because both physical properties (if any exist) and social representations, or any hybrid mixture of them, are treated identically: as a competence of an actant that may or may not help it to build associations with other actants.

Second, by transcending the distinction between the social and natural/ technical (or between signs and things), hybrid constructivism is able to state generalisations about affordances and constraints that could not be stated if this distinction were to be maintained, because then the required vocabulary would not be available to make such generalisations. In a hybrid framework, it is easier to see how a physical artifact translates human behaviour into a more durable form, for example, or how a human groom and a door closer are instances of the same process of delegation. As a flipside to this, analyses are also less cluttered by distinctions (between signs and physical objects, social actions and physical behaviour, etc.) that are irrelevant to the analysis.

I agree that these are both real advantages of hybrid constructivism. However, I believe that they are not decisive in its favour. Although the vocabulary of hybrid constructivism enables generalisations on the affordances and constraints of artifacts that are not possible in a vocabulary that maintains the natural-social distinction, it pays the price of forfeiting detail. Because it cannot refer to things as social or natural or technical, because it cannot use these traditional categories, it cannot discern any meaningful distinctions between physical and semiotic force, or between physical and social processes, and any relevant differences between the two cannot be made to play a role in the analysis. For example, the strategies by which human actors may try to resist symbolic force and physical force are surely different. Resistance to physical force may result in the disabling or modification of artifacts, whereas resistance to the force of symbols may result in the production of alternative symbols (cf. Pfaffenberger 1992). Similarly, it seems to be relevant whether prescriptions target human or nonhuman actants. Human actants have a richer behavioural repertoire by which they can respond to prescriptions, and humans may have various intentions, beliefs and motivations that may be relevant in the analysis. In a hybrid vocabulary, these differences between humans and nonhumans are obscured in the interest of symmetrical treatment.

Since the mid-1990s, actor-network theorists have moved beyond some of the basic tenets of ANT as it was developed up until the early 1990s (Law and Hassard 1999; Lee and Brown 1994). Specifically, many now do not want to 
claim that ANT contains a coherent set of principles, but emphasise the diversity of approaches in ANT, and the diversity of ways in which links between actants in networks can be created by the analyst, and the need to tell multiple possible inconsistent narratives about technologies rather than a single consistent narrative. Parallel to this, there has been greater emphasis on multiplicity and difference, on the disorder of networks, and the heterogeneous ways in which actants take on actantional roles and are multiply realised in different, partially overlapping networks. These recent approaches, however, still make use of limited hybrid vocabularies that fail to recognise finegrained differences that appear relevant in the much richer traditional vocabulary in which differences between the social, the natural and the technical are acknowledged.

\section{Differentiated constructivism}

The defense of hybrid constructivism rests in part on the supposition that it is the only alternative to realism and social constructivism. I now want to argue that a fourth position is possible, differentiated constructivism, which avoids some of the weaknesses of realism and social constructivism. Differentiated constructivism is the standpoint that the agency of artifacts results partly from the material design structure of artifacts (pace realism) and partly from social processes (pace social constructivism). It is believed that, although it is often difficult to separate these two contributing factors (pace hybrid constructivism), this kind of separation usually can and should be included in the analysis. Just like hybrid constructivism, differentiated constructivism neither privileges the natural or technical nor the social or symbolical. Yet, it holds that some affordances and constraints correlated with artifacts are physical in nature, whereas others result from social representation. It also holds that affordances and constraints may be in part physical and in partsocial, and that it is possible to distinguish between these respective parts in analyses. Hence, some constraints are physical, others are socially constructed, and yet others are a combination of physical and social factors. Differentiated constructivism is hence a position on the agency of artifacts that maintains the distinction between the physical/technical and the social/symbolical (and hence rejects the generalised principle of symmetry), but also rejects exclusively realist and social constructivist accounts of affordances and constraints.

To illustrate this position, let us reconsider the (social constructivist) analysis of demarcation of social status by the Victorian hallway bench (section 2). In a differentiated constructivist analysis, it might be analysed that the 
bench has certain objective properties. For example, it is hard and does not have many elegant carvings. These objective properties constrain certain perceptions (social representations) of the bench, for example, that it is plain. Plainness was a social construction that was associated with the lower classes in Victorian times. Because only people from the lower classes were told to use these benches, they therefore functioned as a means to mark social class. The difference between this analysis and the social constructivist analysis is that it goes outside social representations in the analysis of this constraint to appeal to "objective" physical properties of the artifact. These play a role, along with social representations, in the constitution of affordances and constraints.

Similarly, a differentiated constructivist analysis of political constraints imposed by the atom bomb would go along with the social constructivist supposition that the organisation of an authoritarian security network around the bomb is motivated by social representations that attribute lethal properties to it. It would then go on to analyse these social representations to be dependent on the presence of actual lethal properties in the bomb. ${ }^{7}$ Differentiated constructivists may grant that, for some affordances and constraints, the physical properties of the artifact play a wholly arbitrary role. Thus, the fact that pink baby clothes for girls promotes gender stereotypes may be rightly analysed as resting on a cultural convention or symbolism that arbitrarily connects perceptions of pink with stereotypical feminine traits. Still, then, it may be emphasised that the perceived pinkness of the clothes is not an arbitrary social construction, but is based on actual physical properties of the clothes.

The above examples illustrate a variety of differentiated constructivism that is closer to social constructivism than to realism in that it is still ultimately social representations that generate affordances and constraint, even if these social representations are themselves constrained by actual physical properties of artifacts. Hence, these physical properties only issue indirect constraints. A variety of differentiated constructivism that is closer to realism holds that physical properties of artifacts sometimes impose more direct constraints, that is, constraints unmediated by social representations. Often, these are constraints that result from the fact that the artifact exerts physical force: it makes certain states of affairs physically improbable or even impossible, or makes them physically probable or even necessary. For example, a locked door imposes the constraint that those who open it have to have a fitting key (or have another means to take away the physical resistance of the door that prevents them from entering). This constraint is in place because the door will physically resist anyone from entering who does not have a fitting key. How the door is represented by that person appears to be irrelevant to this fact. 
Or consider the modern Western sofa, which has separate seat cushions that define distinct personal spaces and hence work to respect and perpetuate modern Western culture's emphasis on individuality and privacy. In part, this perpetuation of privacy derives from perceptions of the divisions between the cushions, and the learned convention that it is impolite to cross these when sitting next to someone with whom one is not intimate. However, these divisions do not just generate particular social representations, they also constitute a gap that makes it less comfortable to cross it, and hence in this way exerts some amount of physical force that stimulates people to remain within the confines of one seat cushion. Similarly, a heavy hotel key exerts a weak physical force on guests, stimulating them to return it to the front desk when leaving. Sometimes, this force may just serve a symbolic function, by reminding them to return the key. In other cases, the perceived discomfort may cause guests to return the key that they would otherwise have preferred to take with them. ${ }^{8}$

Physical properties of artifacts do not always work to make things happen or prevent them from happening by exercising physical force. They may also make it possible for new things to happen by physically creating new opportunities. In an environment in which human actors actively seize this new opportunity, technology may be interpreted as imposing a constraint. For example, the installation of running water and washing machines in houses on Ibiza, Spain, made it possible for people to do their washing and laundering inside. Because many inhabitants preferred doing this to using the public fountain and washbasin, these fountains and washbasins were consequently abandoned. As a result, the social ties between Ibizans weakened. This social constraint is not physically necessitated by the new technology, but is afforded by it, and in the right environment, such an affordance turns into a constraint.

What, finally, makes differentiated constructivism a constructivist position, rather than a variety of realism? This, I submit, depends on how these two positions are defined. Nothing important hinges on it. I earlier defined the realist position as holding that affordances and constraints have their basis in the material design structure of artifacts, and the constructivist position as holding that affordances and constraints are partially or wholly the product of processes external to the artifact. I also claimed that realists normally play down the role of social representation in human-artifact interactions and that human agents normally respond to artifacts on the basis of their objective physical features. Now, differentiated constructivism retains the realist premise that artifacts have real physical properties that can be analysed by the analyst independently of third-person social representations of these properties. For some, it would suffice to call this position "realism" instead. However, 
I put more weight on the fact that differentiated constructivism, unlike mainstream realism, assigns a major role to social representation processes external to the artifact, and holds that human agents normally respond to such social representations in their interaction with artifacts, rather than (just) to their objective physical qualities.

I want to claim, finally, that it may not be necessary to choose between a hybrid or a differentiated constructivist account. Both may have a role in analysis. With a hybrid vocabulary, it is possible to state broader generalisations in the analysis of affordances and constraints. The analysis may then be extended and deepened by employing the vocabulary of differentiated constructivism, which retains a number of distinctions that disappear within a hybrid vocabulary. This latter analysis may reveal more specific mechanisms of translation, delegation, and prescription that are difficult to uncover within the generic vocabulary of hybrid constructivism. Indeed, in his analyses, Latour makes frequent use of asymmetrical terms in addition to his hybrid terminology, by describing actants as "human" or "nonhuman", by attributing intentions and desires to humans, and by calling things and events "technical" or "social". These descriptions often seem to deepen, rather than undermine, his analyses.

\section{Conclusion}

Hybrid constructivists rightly point out that agency is not produced by artifacts themselves, nor by social processes external to artifacts. It is the product of actor-networks in which the physical behaviour of artifacts and the social behaviour of humans blend together into a knot that is often difficult to untie. Both humans and nonhumans are agents ("actants") in that they have a causal or structural role within the network. Yet, I have argued, the vocabulary of hybrid constructivism is too general to untie the knot of actor-networks completely. A differentiated constructivist approach can more specifically point to the relative contributions of artifacts, social representations, and other structures and processes.

\section{Notes}

1 The factual accuracy of the case has been contested by Woolgar and Cooper (1999), who claim that the bridges in question did not in fact work to block bus access to Long Island. I will use the case here only as a hypothetical example of 
how different approaches may treat the political role of an artifact like a bridge, assuming, for the sake of discussion, that they actually block bus access.

2 Indeed, the setting has changed since the 1960s. One change since then is the emergence of the camper van. The bridges now also discriminate against owners of camper vans, who cannot pass under them.

3 Well-known work within a hybrid constructivist framework has been performed by Latour, Akrich, Callon, and Law (all adherents of actor-network theory). Bijker has also converted to this position (Bijker 1992). Bijker, however, still calls his position "social constructivism", unlike Latour, who defines social constructivism according to my above definition, and holds the principle of generalised symmetry to be incompatible with social constructivism. Cf. Callon and Latour (1992).

4 Latour and Akrich sometimes appear to use the term "translation" more broadly for any transfer of action from one group of actants to another, whether or not these latter actants perform the action more efficiently or effectively.

5 Prescriptions are similar to what Pfaffenberger (1992) calls affordances. Notice that "affordance" is also used as a synonym of "prescription" by Latour.

6 The strength of an artifact constraint, or prescription, is hence in Latour's theory relative to the competencies and attunements of actants that it is aimed at. Artifact constraints may, however, also be called weak or strong in a more absolute sense, that is, relative to "normal" or "average" actants. The Long Island bridges may then be said to issue a strong constraint, in that average buses will not be able to resist them.

7 Notice that such analyses would then not only break with the generalised principle of symmetry of hybrid constructivism, which holds that humans and nonhumans must be treated in the same way, but also with the social constructivist principle of symmetry, according to which no assumptions are made in analyses about the truth of scientific claims or about the actual properties of technologies. It hence assigns to the analyst the competence to know the difference between reality and representation (or between "good" and "bad" representations). As will be argued later on, the analyst will not always be in a position to claim this competence, but may sometimes legitimately claim it.

8 Notice that, as artifacts become part of everyday life, constraints issued by them that result from their capacity to exercise physical force may no longer be issued by their actual exercise of physical force, but by the perception of human agents that the artifact has this capacity. Human agents will then often act in accordance to the constraint so that they are not subjected to physical force. So most people will not try to walk through doors that they know to be locked and for which they do not have a key, and if they believe their key to be heavy, hotel guests may decide to return it to the front desk before lifting it. 